\title{
Modulation of ventral striatal activity by cognitive effort
}

\author{
Ekaterina Dobryakova ${ }^{\mathrm{a} 1}$, Ryan K Jessup ${ }^{\mathrm{b}}$, and Elizabeth Tricomi ${ }^{\mathrm{a}^{*}}$
}

${ }^{a}$ Department of Psychology, Rutgers University - Newark, 101 Warren Street, Newark, New Jersey, ${ }^{\mathrm{b}}$ Department of Management Sciences, Abilene Christian University

* Corresponding author at: Department of Psychology, Rutgers University - Newark, 101

Warren Street, Newark, New Jersey, 07102. Email Address: etricomi@ rutgers.edu

\footnotetext{
${ }^{1}$ Present Address: Kessler Foundation, 120 Eagle Rock Ave, East Hanover, New Jersey 07936.
} 


\begin{abstract}
Effort discounting theory suggests that the value of a reward should be lower if it was effortful to obtain, whereas contrast theory suggests that the contrast between the costly effort and the reward makes the reward seem more valuable. To test these alternative hypotheses, we used functional magnetic resonance imaging (fMRI) as participants engaged in feedback-based learning that required low or high cognitive effort to obtain positive feedback, while the objective amount of information provided by feedback remained constant. In the low effort condition, a single image was presented with four response options. In the high effort condition, two images were presented, each with two response options, and correct feedback was presented only when participants responded correctly to both of the images. Accuracy was significantly lower for the high effort condition, and all participants reported that the high effort condition was more difficult. A region of the ventral striatum selected for sensitivity to feedback value also showed increased activation to feedback presentation associated with the high effort condition relative to the low effort condition, when controlling for activation from corresponding control conditions where feedback was random. These results suggest that increased cognitive effort produces corresponding increases in positive feedback-related ventral striatum activity, in line with the predictions made by contrast theory. The accomplishment of obtaining a hard-earned intrinsic reward, such as positive feedback, may be particularly likely to promote reward-related brain activity.
\end{abstract}

Keywords: trial-and-error learning, striatum, effort, effort discounting, contrast theory, VMPFC 


\section{Introduction.}

Human behavior is motivated by a wide variety of goals, from simple goals, such as getting to work on time, to more complex goals, such as finishing a major project. The reward experienced when a goal is achieved depends on the value one places on the goal. The ventral striatum (VS) has been shown to play an important role in processing goal values, both for extrinsic, or tangible, outcomes (such as food rewards and monetary gain or loss) (Knutson et al., 2001; Kurniawan et al., 2013; Tricomi \& Lempert, 2015) and for intrinsic, or nontangible, outcomes (such as positive and negative feedback during learning) (Ullsperger \& von Cramon, 2003; Lutz et al., 2012; Dobryakova \& Tricomi, 2013; DePasque Swanson \& Tricomi, 2014). However, goal value is influenced not only by expected outcomes, but also by the effort required to achieve those outcomes (Braver et al., 2014; Westbrook \& Braver, 2015; Kurniawan, Guitart-Masip, Dayan, \& Dolan, 2013). Depending on the context in which the goal has to be attained, more or less effort might be expended to achieve a goal. For example, acquiring a good grade for a class that required 20 hours of work per week might be more rewarding than getting the same grade for a class that required only 5 hours of work per week. In this example, the same outcome is preceded by different amounts of effort. Thus, the experienced reward value of an outcome is context-dependent and related to the amount of effort expended to achieve a reward.

There are two theories that make opposite predictions about how effort exerted during goal-directed actions impacts outcome valuation. According to effort discounting theory, effort decreases outcome value, such that rewards from effortful actions are devalued due to the greater amount of effort required to perform them (Botvinick et al., 2009). Thus, in the above example, a good grade for a class that required only 5 hours of work per week would be more rewarding 
than a good grade that required 20 hours of work per week. This principle has been shown to hold in the context of both physical (Kurniawan et al., 2010, 2013; Skvortsova et al., 2014) and cognitive effort requirements (e.g. Kool et al., 2010). In accordance with effort discounting theory, human neuroimaging studies show that outcomes associated with greater effort lead to decreased activity of the VS (Botvinick and Rosen, 2009, Kool et al., 2010, McGuire and Botvinick, 2010).

On the other hand, according to contrast theory, outcomes resulting from increased effort would be valued more due to a greater contrast between the aversive action and the rewarding nature of the outcome (Singer et al., 2007; Zentall \& Singer, 2007). Thus, in the above example, a good grade for a class that required 20 hours of work per week would be more rewarding than a good grade that required only 5 hours of work per week. While neuroimaging evidence is lacking, contrast theory would predict increased activation of the VS in association with outcomes that follow effortful actions.

The focus of previous effort-based decision-making studies has primarily been on how extrinsic (e.g., monetary) outcomes are anticipated and valued after different degrees of effort (e.g. Botvinick \& Rosen, 2009; Croxson et al., 2009; Schmidt et al., 2012), and whether individuals prefer, or are more likely to choose, high vs. low effort actions (e.g. McGuire \& Botvinick, 2010; Kool \& Botvinick, 2013). Less is known about the processing of less tangible outcomes, such as the knowledge that one has answered correctly. Unlike money, this sort of performance feedback has no value outside of the task, and therefore, its value is quite subjective (Labroo \& Kim, 2009; Braver et al., 2014). Thus, in the current study, we examined the effect of varying cognitive effort demand on VS activity and outcome valuation during learning with performance-related feedback. 
Participants were presented with a trial-and-error learning task, in which they had to learn to associate abstract images with specific responses based on the feedback presented after each trial. Cognitive effort was manipulated to be greater in one condition than the other through increased difficulty. As both the affective and informative aspects of feedback activate the striatum (Tricomi \& Fiez, 2012; Smith et al., 2016), we kept the initial amount of information provided by feedback the same across conditions. Further, two additional conditions were presented that did not require cognitive effort. For these two conditions, participants had to respond with either one or two button presses, without feedback reflecting their performance accuracy. This design allowed us to compare 1) neural activation associated with outcomes after high and low cognitive effort, as well as 2) neural activation associated with outcomes obtained without any cognitive effort. On the basis of the competing theories, we had two alternative hypotheses: the effort discounting hypothesis predicts that rewards earned after high cognitive effort would produce less VS activation than rewards earned after low cognitive effort, whereas the contrast theory hypothesis predicts that rewards earned after high cognitive effort would produce more VS activation than rewards earned after low cognitive effort.

\section{Methods.}

\subsection{Participants.}

Twenty-four individuals participated in the experiment for $\$ 50$ each in monetary compensation. All participants provided written informed consent. Data from one participant were not included in the main analysis due to a diagnosed brain abnormality. Data from one other participant were not included due to the participant not being able to finish the experiment. Therefore, data from 22 participants were analyzed ( 9 females; age $M=23.3$ years, $S D=5.4$ ). The research was approved by the Institutional Review Board of Rutgers University. 


\subsection{Materials.}

A 3-Tesla Siemens (Erlangen, Germany) Trio scanner was used to acquire all MRI data. Behavioral data acquisition and stimulus presentation was administered using the "E-Prime" software (Schneider et al., 2002).

\subsection{Procedure.}

\subsubsection{Scan session.}

A T1-weighted pulse sequence was used to collect structural images in 41 contiguous slices (3x3x3 mm voxels). Similarly, 41 functional images were collected using a single-shot echo EPI sequence amounting to 142 acquisitions $(\mathrm{TR}=2500 \mathrm{~ms}$, TE $=25 \mathrm{~ms}, \mathrm{FOV}=192 \mathrm{~mm}$, flip angle $\left.=80^{\circ}\right)$ tilted $30^{\circ}$ from the AC-PC line (Deichmann et al., 2003).

\subsubsection{Behavioral paradigm.}

Participants had to learn through trial-and-error to associate abstract images with one of the four specific buttons. Specifically, participants were presented with two learning conditions that represented high and low cognitive effort conditions, and two random feedback conditions that required no cognitive effort but only a motor response. In the 1-step learning condition (low cognitive effort), participants were presented with one abstract image and had to respond with one of the four buttons, only one of which led to the presentation of the correct feedback (green $\sqrt{ }$ ). The other three buttons led to the presentation of the incorrect feedback (red X) (Figure 1).

During the 2-step learning condition (high cognitive effort), participants were presented with two abstract images, side by side (Figure 1). Participants had to respond to both images. First, participants had to respond to the image on the left side of the screen with buttons 1 or 2. Then, participants had to respond to the second image on the right side of the screen with buttons 3 or 4. Participants were presented with cumulative feedback after they responded to both 
images. Correct feedback was presented only when participants responded correctly to both images. At all other times, incorrect feedback was presented. The side each of the images was presented on remained consistent throughout the experiment. Importantly, feedback provided the same amount of information in both the 1-step and 2-step learning conditions. That is, since there are four possible responses per trial in both learning conditions, there is an initial $25 \%$ chance of being correct in each trial (as learning progresses, the observed probability of making a correct response differs based on accuracy). The 2-step condition required more effort than the 1-step condition, however, because it places more demands on working memory, as it requires two images and two responses to be held and updated in working memory.

The 1-step and 2-step random conditions resembled the learning conditions described above in all respects, except that feedback did not reflect participants' accuracy (i.e. correct and incorrect feedback presentation was random). Participants were informed that feedback during random conditions would not reflect their performance and that there was no correct response associated with the stimulus. They were also instructed to press any of the four buttons during these conditions. As the control conditions should not require cognitive effort, they control for other differences between the 1-step and 2-step conditions, such as the need to make two button presses in the 2-step condition.

Each trial started with a fixation point (jittered 1-6 seconds; 4.5 seconds on average, uniform distribution) that contained a label informing participants of the condition they were in. The stimulus screen was presented for four seconds and, during this time, participants had to indicate their response. At the end of the $4 \mathrm{~s}$, the feedback screen was presented for one second. Four different stimuli (or pairs of stimuli, for the 2-step conditions) were shown in each condition (constituting a block of 4 trials), and each block was presented a total of 12 times each 
over the course of the experiment, amounting to 48 trials of each condition (192 total trials per participant). There was no inter-stimulus interval (ISI) from the response screen to feedback, as previous research has shown that delaying feedback can decrease reliance on the striatum (Foerde \& Shohamy, 2011; Foerde et al., 2013). A fixation point was presented in between the different blocks (jittered 1-6 seconds; 4.5 seconds on average, uniform distribution). The stimuli for each condition were consistent across the study, but trial order and block order were pseudorandomized for each participant, with each stimulus appearing four times in each 6-minute scanning session.

\subsubsection{Questionnaires.}

At the end of the experiment, participants were given a questionnaire that inquired: 1) whether they preferred feedback after the 1-step or the 2-step learning conditions, 2) during which condition they felt more engaged in the task, 3) in which condition learning was harder and 4) whether random feedback presentation was rewarding. Questions 1 and 4 were specifically targeted at understanding whether participants' preferences support effort discounting (1-step learning condition; 1-step and 2-step random conditions) or contrast theory (2-step learning condition). Questions 3 was a manipulation check, so that we could see whether the 2-step learning condition was perceived as more effortful.

\subsection{Data analysis.}

\subsubsection{Behavioral data.}

Accuracy data from the two learning conditions were analyzed by means of two-tailed paired t-tests. Since the random conditions did not involve any learning, and it was not possible to correctly respond to stimuli, accuracy results were not analyzed for this condition.

\subsection{2 fMRI data.}


Preprocessing of the functional data was performed using the Brain Voyager QX software (Version 2.4.2.2; Brain Innovation, Maastricht, the Netherlands). Preprocessing included three-dimensional correction for motion using six parameters (for the three translation and three rotation directions). Images were spatially smoothed ( $8 \mathrm{~mm}, \mathrm{FWHM})$, voxel-wise linearly detrended, and passed through a high-pass, temporal filter of frequencies ( 3 cycles per time course). The resulting data were normalized to the Talairach stereotaxic space (Talairach \& Tournoux, 1998). Ventral striatum coverage was verified for all subjects.

\subsubsection{GLM analysis.}

After image preprocessing, a whole brain analysis was performed on the data. A randomeffects general linear model (GLM) analysis was performed on the 1s time period of feedback presentation. The predictors of interest were: positive 1-step feedback, negative 1-step feedback, positive 2-step feedback, and negative 2-step feedback for the learning conditions; and positive 1-step feedback, negative 1-step feedback, positive 2-step feedback, and negative 2-step feedback for the random conditions. The regressors were convolved with a canonical hemodynamic response function. The missed trials and six motion parameters were also included in the model as regressors of no interest, as well as the cue event, starting at cue onset with reaction time as the event duration (the reaction time to the second stimulus presentation was used as the duration in the 2-step conditions). The GLM analysis resulted in identification of regions of interest (ROIs) thresholded at $\mathrm{p}<0.001$, along with a contiguity threshold of 3 ( $3 \times 3 \times 3$ $\mathrm{mm}^{3}$ ) contiguous voxels, determined using the cluster-level statistical threshold estimator in Brain Voyager (Version 2.3; Brain Innovation, Maastricht, the Netherlands). This method performs whole-brain correction for multiple comparisons and produces a cluster level false positive alpha rate of 0.05. A whole brain ANOVA was conducted in order to detect the effects 
of valence, difficulty, and contingency associated with the 1-step and 2-step learning and random conditions.

To address the main question of the study, we aimed to determine whether the same voxels were sensitive to both feedback value (positive versus negative feedback) and effort requirements (high versus low effort). We thus performed a contrast of positive feedback versus negative feedback, collapsing across difficulty and contingency, and identified a large region centered in the ventral striatum. We then performed a second-order analysis on the parameter estimates in the identified voxels, comparing positive feedback from the conditions of the two effort levels [(2-step learning positive - 2-step random positive) - (1-step learning positive - 1step random positive)]. A similar contrast with negative feedback was performed. Further, based on questionnaire data about feedback preference, we looked at whether individuals preferring feedback after either the 1-step learning or the 2-step learning conditions had increased feedback-related VS activation after the corresponding condition, and whether there were between-group differences in VS activation as a function of feedback preference.

\subsubsection{Prediction error (PE) analysis.}

As the 2-step learning condition might be more difficult than the 1-step learning condition, prediction error (PE), or the difference between the expected and actual outcome, could differ between conditions over time, as differences in difficulty emerge, and positive feedback becomes less expected for the 2-step learning condition. To account for potential PErelated differences between conditions, PE was included in a second GLM analysis as a parametric modulator (GLM 2). First, we used the observed choice and accuracy data to obtain the best-fit learning rates $\lambda$ and $1 / \theta$ parameters for all four conditions, using the following variant of Q learning: 


$$
Q_{i}(t)=Q_{i}(t-1)+\lambda \cdot\left(F_{i}(t-1)-Q_{i}(t-1)\right) \quad \text { Equation } 1 .
$$

Here, participants learn $Q_{i}(t)$, indicating the value of stimulus $i$ on trial $t$. The stimulus values were updated using $F_{i}(t-1)$ which represented the feedback value ( 0 or 1 for negative or positive feedback, respectively) for stimulus $i$ on the previous trial. If that stimulus was not observed on the previous trial, then we used the feedback value from the previous trial on which it was observed, or 0 if this was the first trial on which it was observed. The learning or updating rate parameter $\lambda$ was allowed to vary from 0 to 1 ; large values of $\lambda$ indicate faster updating whereas small values indicate slower updating.

To predict choice probabilities we used the softmax variant of the Luce choice rule (Luce, 1959):

$$
P_{i}(t)=e^{Q_{i}(t) / \Theta} / \sum_{i}^{I} e^{Q_{i}(t) / \Theta} \quad \text { Equation } 2 .
$$

The probability $P$ of choosing option $i$ on trial $t$ is obtained by first exponentiating the product of the $Q$ value for that option and the inverse temperature parameter $1 / \theta$. Second, this value is then divided by the sum over all options $i$ of the exponentiated product of the $Q$ value for each option and the inverse temperature parameter $1 / \theta$. The inverse temperature parameter was allowed to vary from 0.01 to 10 ; large values of $1 / \theta$ indicate more deterministic choosing whereas small values indicate more random choosing.

We found the best fitting parameters for each condition separately by maximizing the negative log likelihood of the behavior over all participants (a fixed effects approach), given the model. The conditions were fit separately due to the expected (and observed) differences in choice accuracy, reflecting the possibility that participants either learned at different rates or 
differed in the stochasticity of their choices between the different conditions, a common technique when responses differ significantly (Busemeyer \& Stout, 2002; Schmidt et al., 2014). To determine the fit quality of the model in the different conditions, we then calculated the Bayesian Information Criterion (BIC) (Schwarz, 1978) - a criterion that penalizes additional free parameters - for each condition, and then compared each to the BIC from a 0-parameter baseline model that assumes participants merely choose options at random. For a model to outperform the baseline model on the BIC, participants must choose according to a pattern which the model efficiently (i.e., in terms of free parameters) captures. The best fitting parameters for each model in each condition and their BIC values are shown in Table 1. In the BIC formulation used here, lower values indicate a better fit to the behavior. As can be seen in Table 1, the learning model outperforms the baseline model for both learning conditions, indicating that there is indeed a pattern in their choice behavior and the learning model efficiently captures it. Since the BIC values for the two random conditions were inferior compared to the BIC for the 0-parameter model (thereby indicating that behavior in a random condition is not well described by a learning model, as would be expected), we conducted the GLM analysis using the PE regressors from the two learning conditions only ${ }^{2}$. Using the best fitting parameter values, we computed the PE values for each trial. The resultant PE values were used as parametric modulators of task-related activation, modeled at the onset times of outcome presentation for the 1-step and 2-step learning conditions and convolved with a hemodynamic response function.

\section{Results.}

\subsection{Behavioral results.}

\footnotetext{
${ }^{2}$ We also fit all the subject learning data using a single learning rate parameter, yielding a BIC value of 5189. This value is greater than and hence provides an inferior fit compared to the sum of the BIC scores for the two separate learning conditions.
} 


\subsubsection{Accuracy.}

Figure 2 displays accuracy results for the two learning conditions. A two-tailed paired ttest revealed a significant difference in accuracy between the two conditions, showing that participants learned significantly better in the 1-step learning condition than in the 2-step learning condition, $\mathrm{t}(21)=5.37, \mathrm{p}<0.001$.

\subsubsection{Reaction Time $(R T)$}

A within-subjects ANOVA was performed on participants' RT with difficulty (2-step vs. 1-step) and contingency (learning vs. random) as within-subject factors. The ANOVA revealed a significant interaction of difficulty and contingency $(F(21,1)=6.95, \mathrm{p}<0.05)$ and a main effect of difficulty $(F(21,1)=18.6, p<0.0001)$ and of contingency $(F(21,1)=248.73, p<0.0001)$ (Supplementary Figure 1). Participants responded faster during the 1-step conditions compared to 2-step conditions. Similarly, participants responded faster during the random conditions compared to the learning conditions, especially for the 2-step condition.

\subsubsection{Questionnaire data.}

Half of the participants indicated that they were most engaged in the task during the 1step learning condition (11 out of 22), while almost half of participants indicated that they were most engaged in the task during the 2-step learning condition (9 out of 22). The rest of the participants did not provide a clear response to this question. Similarly, more than half of the participants (13 out of 22) indicated that feedback in the 2-step learning condition was more rewarding, while 7 out of 22 indicated that feedback in the 1-step learning condition was more rewarding. Two other participants did not provide a clear response to this question. All participants responded that learning during the 2-step learning condition was more difficult. 
More than half of participants (14 out of 22) indicated that random feedback was not rewarding to them.

\section{2 fMRI results.}

3.2.1 Whole-brain results (GLM 1). A whole-brain, voxel-wise within-subjects ANOVA was performed with difficulty (2-step vs. 1-step), contingency (learning vs. random) and valence (positive vs. negative) as within-subject factors. An interaction of difficulty by contingency by valence, as well as the difficulty by contingency, resulted in activation of the ventromedial prefrontal cortex (VMPFC) (Supplementary Tables 1a-b). An interaction of contingency by valence resulted in VS activation (Supplementary Table 1c). The interaction results of difficulty by valence are presented in Supplementary Table 1d. The results of the main effect of difficulty, contingency, and valence are presented in Supplementary Tables 2a -2c.

\subsubsection{High effort versus low effort.}

To determine whether the same region is sensitive to feedback value (positive versus negative feedback) and effort requirements (high versus low effort), we first performed a contrast to identify voxels sensitive to feedback value in general. That is, positive feedback presentation was contrasted with negative feedback presentation, while collapsing across difficulty and contingency. This contrast revealed extensive bilateral striatal activation and VMPFC activation, in addition to other cortical regions (Figure 3; Table 2). Since we had a strong a priori hypothesis focused specifically on the VS, we performed the comparison of high effort versus low effort feedback presentation on the VS voxels (cluster extent of 886 voxels) identified by this contrast, while controlling for the random conditions. Significant differences were detected bilaterally: right VS: $\mathrm{t}(21)=3.4, \mathrm{p}<.005$; left VS: $\mathrm{t}(21)=3.4, \mathrm{p}<.005$ (Figure 4). A similar 
comparison with negative feedback did not reveal any reliable effects (right VS: 0.2, p=0.9; left VS: $\mathrm{t}(21)=0.8, \mathrm{p}=0.4)$.

Further, we hypothesized that individuals with the preference for the low effort condition (1-step learning) would show greater activation during the feedback presentation of the 1-step learning condition, while individuals with the preference for the high effort (2-step learning) would show greater activation during the feedback presentation of the 2-step learning condition. Parameter estimates from the above contrast were entered into a repeated measures ANOVA with preference (1-step vs. 2-step) as a between-subject factor and effort (high vs. low) as a within-subject factor. Instead of the hypothesized interaction, we observed a significant main effect of effort (right VS: $\mathrm{F}(21,1)=13.89$, p<.005; left VS: $\mathrm{F}(21,1)=11.2, \mathrm{p}<.005)$, consistent with the above finding of increased activity for high compared to low effort. However, a posthoc paired-samples t-test revealed no between-group differences (1-step preference vs. 2-step preference group during low effort condition: $\mathrm{t}(18)=0.53, \mathrm{p}=0.6 ; 1$-step preference vs. 2 -step preference group during high effort condition: $\mathrm{t}(18)=0.9, \mathrm{p}=0.4)$.

\subsubsection{Prediction Error analysis (GLM 2).}

The PE analysis revealed a significant effect of PE associated with the 1-step learning condition in the right caudate head and other regions in the cortex and cerebellum (Table 3a). There was also a significant effect of PE associated with the 2-step learning condition in bilateral MPFC (BA 10), rACC (BA 24), and the insula (Table 3b). No significant striatal activation was detected in association with PE for the 2-step learning condition.

Contrasting the effect of PE for the 2-step learning condition versus PE for the 1-step learning condition $\left(\mathrm{PE}_{2 \text {-step learning }}>\mathrm{PE}_{1 \text {-step learning }}\right)$ did not reveal any significant striatal activation $(\mathrm{t}(21)=1.04, \mathrm{p}=0.31)$. This contrast revealed activation in the VMPFC as well as other cortical 
areas (Table 3c), suggesting that activity in these regions was more strongly correlated with PE in the 2-step than 1-step conditions. A contrast of the 2-step learning versus the 1-step learning conditions, while controlling for PE, did not reveal any significant effects in the striatum $(\mathrm{t}(21)=0.74, \mathrm{p}=0.47)($ Table $3 \mathrm{~d})$.

\section{Discussion}

In this study, we looked at how cognitive effort influences valuation of intrinsic outcomes (performance-related feedback) and associated striatal activity during a trial-and-error learning task. Specifically, cognitive effort was manipulated by varying the working memory load required in different conditions, by presenting performance-related feedback either after a response to a single stimulus or after a sequence of two responses to two different stimuli. In addition, two conditions in the current experiment did not require any cognitive effort and resulted in random feedback presentation, thus providing a visuo-motor control for the 1- and 2step conditions. Consistent with previous findings (Elliott et al., 1997; Delgado et al., 2000; Tricomi et al., 2004, 2006; Tricomi \& Fiez, 2008; Dobryakova \& Tricomi, 2013; Sescousse et al., 2013; DePasque Swanson \& Tricomi, 2014), we observed a robust main effect of valence in the dorsal and ventral striatum, driven by significant differences between positive and negative feedback presentation in all four conditions. Furthermore, in the same voxels that showed a sensitivity to positive versus negative feedback, we also observed enhanced VS activation in association with the more difficult and cognitively effortful condition, i.e., the feedback presentation during the 2-step learning condition.

The 2-step learning condition was more cognitively demanding, as reflected in significantly lower performance on the 2-step learning condition compared to the 1-step learning condition. Additionally, all participants reported that the 2-step learning condition was more 
difficult to learn than the 1-step learning condition, suggesting that to obtain positive feedback during this condition, participants had to exert greater cognitive effort than during the low cognitive effort condition. In conjunction with these behavioral results, fMRI results revealed greater VS activation to positive feedback in the 2-step learning condition versus the 1-step learning condition, while controlling for the random feedback conditions. This result supports contrast theory, which suggests that high effort increases the subjective value of rewarding outcomes, leading to increased striatal activation.

These results, however, are not in line with previous research that has found evidence that the activation of VS reflects effort discounting (Botvinick et al., 2009; Croxson et al., 2009; Kool et al., 2010; Kurniawan et al., 2010). There are several possible explanations for the obtained results. Nuanced differences in our task design compared to other tasks may contribute to the disparities across studies. For example, contrast theory may depend critically on the contingency between the effort and the resulting outcome, since effort that is not seen as necessary to earn a reward is unlikely to enhance outcome value; however, in some paradigms finding support for effort discounting, effort and outcomes have been decoupled (Botvinick et al., 2009). Another difference between the current task and commonly used effort paradigms (e.g., Kurniawan et al., 2010, 2013) is that participants in our task had to exert cognitive rather than physical effort. Physical effort may be less subjective as it can be directly measured with grip devices and force transducers (Liu et al., 2000; Jiang et al., 2012; Meyniel et al., 2013; Skvortsova et al., 2014). However, while some studies have found increased reward-related activation for high cognitive effort (Stoppel et al., 2011; Satterthwaite et al., 2012; Hernandez Lallement et al., 2014; Ma et al., 2014), there are notable exceptions (Botvinick et al., 2009; Westbrook et al., 2013). Thus, it may be that our task, along with other tasks which have found 
increased striatal activation for high cognitive effort, produce increased feelings of competence when effort demands are high, which may result in an enhanced reward response to positive feedback (Ryan \& Deci, 2000b; Mochon et al., 2012).

Further, we used performance-related feedback, rather than more tangible outcomes, such as money or food. Extrinsic rewards are rewarding even in the absence of a task, whereas a green checkmark indicating positive performance feedback is only rewarding in the context of the task. It may be that the subjective value of positive feedback is particularly likely to be positively linked to the effort required to earn it, and the high cognitive effort condition might have triggered motives of achievement and goal striving (McClelland, 1985; Labroo \& Kim, 2009; Braver et al., 2014). Indeed, Ryan and Deci (2000a, 2000b) suggest that humans are innately inclined to seek out challenges, and meeting the challenge in the high effort condition may have caused the increased striatal activation to feedback. Further, there is evidence suggesting that some individuals perceive difficult, and hence challenging, tasks as attractive. For example, DePasque Swanson and Tricomi (2014) showed that striatal activity is modulated by personality traits such as goals to outperform others. While we did not assess individual differences in personality measures in this study, such personality differences may influence the subjective value one assigns to rewards requiring high effort and related brain activity.

Another potential explanation for greater striatal activation in association with positive feedback of the 2-step learning condition could be that it is driven by greater prediction error, the difference between actual and expected outcomes. That is, given that participants' performance in the 1-step learning condition was significantly better than participants' performance during the 2-step learning condition, differences in PE between conditions could conceivably drive the result of stronger activation associated with the 2-step learning condition that was observed. 
However, our prediction error analysis showed no significant effect of PE on striatal activation in the 2-step learning condition, and no difference between conditions in the effect of PE on striatal activation. While unexpected, this result is in line with findings of another study with different levels of effort demands, which found performance-related VS activity that was not explained by task difficulty (Schmidt et al., 2012). Further, Satterthwaite and colleagues (2012) investigated the effect of working memory load on VS activation and observed greater VS activation in association with correct responses in the more difficult condition of a working memory task, which supported the idea that responding correctly during a more difficult task can increase reward response (Satterthwaite et al., 2012). Several other studies show similar results (Lutz et al., 2012; Schouppe et al., 2014). Therefore, without eliminating the possibility that the PE plays a role in the comparison of feedback after the 2-step and 1-step learning conditions, our results suggest that intrinsic motivation to master a challenging task may have had an effect on VS activity and outcome valuation after the high cognitive effort condition, thereby contributing to the enhanced VS activity.

We observed activation of the MPFC, DLPFC and the ACC in association with difficulty and valence. The MPFC has been shown to play an important role in goal-directed behavior and processing of affective information (Krawczyk, 2002; Mitchell, 2011). Evidence suggests that this region is involved in calculating action value and subjective value of outcomes, and can provide affective information about decision options, causing a person to favor a specific outcome option (Kringelbach, 2005; Padoa-Schioppa \& Cai, 2011; Young \& Shapiro, 2011). Thus, this region may be involved in processing the affective information provided by feedback in our task, and possibly in weighing the value of positive feedback relative to the effort costs to achieve it. The DLPFC has been implicated in working memory, planning, reasoning and in 
integration of information over time (Krawczyk, 2002), suggesting it may play a role in updating action-response associations in our task, especially in the more demanding 2-step learning condition. The ACC has been shown to be involved in effort exertion (Walton et al., 2003; Engström et al., 2014) and evaluating effort costs (Croxson et al., 2009; Prévost et al., 2010; Skvortsova et al., 2014). Furthermore, ACC activation reflects the unexpectedness of an outcome, regardless of valence (Jessup et al., 2010; Alexander \& Brown, 2011), and rewards are less expected in our 2-step learning condition, which had a lower observed probability of success. This network of prefrontal regions, together with the striatum, may process feedback value and support the feedback-based associative learning necessary for our task.

\subsection{Limitations}

\subsubsection{Questionnaire results.}

The questionnaire results do not fully support the idea that participants explicitly value intrinsic outcomes after a more effortful condition. As stated above, only slightly more than half of the participants perceived feedback after the 2-step learning conditions as more rewarding, while the others preferred feedback presentation after the easier 1-step learning condition. Yet, both groups displayed greater neural activation to positive feedback for the 2-step than the 1-step learning condition. While self-report might not be the most reliable measure (e.g. no correlation has been found between executive control and self-report measures (Nęcka et al., 2012)), greater activation of the VS cannot be solely explained by the notion that the outcome following the high effort is more valuable. It is possible that the VS is responding to aspects of high effort trials other than value, such as increased arousal or attention. Alternatively, it could be that individual differences in the degree to which a person enjoys a challenge might serve as a mediator for the observed results. Future research will be necessary to determine whether implicit valuation of 
effortfully earned rewards may differ from explicit valuation, or whether other aspects of our high effort condition were responsible for driving activity in the VS for the high effort condition.

Further, we used participants' preferences to divide the sample into two groups.

However, we did not find any differences in striatal activation in association with participants' preferences. This may be due in part to a small sample size of the two groups ( 7 participants preferring feedback after the 1-step learning condition; 13 participants preferring feedback after the 2-step learning condition). Future studies should examine how individual differences (e.g. need for achievement, level of intrinsic motivation) affect outcome preferences and striatal activation after variable degrees of cognitive effort.

\subsubsection{Control conditions}

As during the learning conditions, participants were asked to respond to the cue during random conditions by pressing whichever button they liked. The random conditions were included in the design as control conditions, as they help to reduce potential confounds that may be caused by aspects of the design, such as the need to make two button presses in the 2-step condition. Psychologically, the random conditions should not be perceived as cognitively effortful, and random feedback in these conditions is less likely to be rewarding. While the observed activation to feedback presentation during the random conditions is unexpected (see supplementary materials), having response options might potentially explain the observed activation as it have been shown to be associated with perceived control (Bown et al., 2003; Leotti et al., 2010). Additionally, the VS activation for the 1-step random condition was greater than for the 2-step random condition, which is in line with the idea that conditions that differ only in physical effort may produce a pattern of activation consistent with effort discounting, whereas increased cognitive effort requirements are more likely to produce activation consistent 
with contrast theory. Indeed, in the random conditions in our task, positive feedback would not be expected to be personally meaningful or to produce feelings of competence that might drive increased reward-related activation when participants succeed in a challenging cognitive task.

\subsection{Conclusion}

The results of the current study show that, while individual differences might play a role in outcome interpretation after learning, intrinsic outcomes that follow high cognitive effort during learning drive activation of the VS, a region that plays a key role in the processing of rewarding outcomes. These results are consistent with the notion advanced by contrast theory that rewards earned through high effort have higher subjective reward value than rewards earned through low effort. This is not to say that contrast theory holds in all circumstances, but rather, that whether effort discounts or enhances reward value may depend heavily on context. Contexts that involve cognitive effort to earn intrinsic rewards, such as positive feedback, may be especially likely to increase the subjective value of the earned reward. This may explain why our proudest moments are not instances when rewards fall in our lap, but rather, times when hard work pays off to yield a desired outcome.

Acknowledgments: The authors would like to thank Samantha DePasque and Holly SullivanToole for their helpful comments on the manuscript. This project was supported by grants from the National Science Foundation (BCS 1150708) and the National Institute on Drug Abuse (RO3DA029170) to ET. 


\section{References}

Alexander, W.H. \& Brown, J.W. (2011) Medial prefrontal cortex as an action-outcome predictor. Nat. Neurosci., 14, 1338-U163.

Botvinick, M.M., Huffstetler, S., \& McGuire, J.T. (2009) Effort discounting in human nucleus accumbens. Cogn. Affect. Behav. Neurosci, 9, 16-27.

Botvinick, M.M. \& Rosen, Z.B. (2009) Anticipation of cognitive demand during decisionmaking. Psychol. Res. Forsch., 73, 835-842.

Bown, N.J., Read, D., \& Summers, B. (2003) The lure of choice. J. Behav. Decis. Mak., 16, 297308.

Braver, T.S., Krug, M.K., Chiew, K.S., Kool, W., Westbrook, J.A., Clement, N.J., Adcock, R.A., Barch, D.M., Botvinick, M.M., Carver, C.S., Cools, R., Custers, R., Dickinson, A., Dweck, C.S., Fishbach, A., Gollwitzer, P.M., Hess, T.M., Isaacowitz, D.M., Mather, M., Murayama, K., Pessoa, L., Samanez-Larkin, G.R., \& Somerville, L.H. (2014) Mechanisms of motivation-cognition interaction: challenges and opportunities. Cogn. Affect. Behav. Neurosci., 14, 443-472.

Busemeyer, J.R. \& Stout, J.C. (2002) A contribution of cognitive decision models to clinical assessment: Decomposing performance on the Bechara gambling task. Psychol. Assess., 14, 253-262.

Croxson, P.L., Walton, M.E., O’Reilly, J.X., Behrens, T.E.J., \& Rushworth, M.F.S. (2009) Effort-based cost-benefit valuation and the human brain. J. Neurosci., 29, 4531-4541.

Deichmann, R., Gottfried, J.A., Hutton, C., \& Turner, R. (2003) Optimized EPI for fMRI studies of the orbitofrontal cortex. Neuroimage, 19, 430-441.

Delgado, M.R., Nystrom, L.E., Fissell, C., Noll, D.C., \& Fiez, J.A. (2000) Tracking the hemodynamic responses to reward and punishment in the striatum. J. Neuroph, 84, 30723077.

DePasque Swanson, S. \& Tricomi, E. (2014) Goals and task difficulty expectations modulate striatal responses to feedback. Cogn. Affect. Behav. Neurosci., 14, 610-620.

Dobryakova, E. \& Tricomi, E. (2013) Basal ganglia engagement during feedback processing after a substantial delay. Cogn. Affect. Behav. Neurosci., 13, 725-736.

Elliott, R., Frith, C.D., \& Dolan, R.J. (1997) Differential neural response to positive and negative feedback in planning and guessing tasks. Neuropsychologia, 35, 1395-1404.

Engström, M., Karlsson, T., Landtblom, A.-M., \& Craig, A.D.B. (2014) Evidence of conjoint activation of the anterior insular and cingulate cortices during effortful tasks. Front. Hum. Neurosci., 8, 1071.

Foerde, K., Race, E., Verfaellie, M., \& Shohamy, D. (2013) A role for the medial temporal lobe in feedback-driven learning: evidence from amnesia. J. Neurosci., 33, 5698-5704.

Foerde, K. \& Shohamy, D. (2011) Feedback Timing Modulates Brain Systems for Learning in Humans. J. Neurosci., 31, 13157-13167.

Hernandez Lallement, J., Kuss, K., Trautner, P., Weber, B., Falk, A., \& Fliessbach, K. (2014) Effort increases sensitivity to reward and loss magnitude in the human brain. Soc. Cogn. 
Affect. Neurosci., 9, 342-349.

Jessup, R.K., Busemeyer, J.R., \& Brown, J.W. (2010) Error effects in anterior cingulate cortex reverse when error likelihood is high. J. Neurosci., 30, 3467-3472.

Jiang, Z., Wang, X., Kisiel-sajewicz, K., Yan, J.H., \& Yue, G.H. (2012) Strengthened functional connectivity in the brain during muscle fatigue. Neuroimage, 60, 728-737.

Knutson, B., Adams, C.M., Fong, G.W., \& Hommer, D. (2001) Anticipation of increasing monetary reward selectively recruits nucleus accumbens. J. Neurosci., 21, art. no.-RC159.

Kool, W. \& Botvinick, M. (2013) The intrinsic cost of cognitive control. Behav. Brain Sci., 36, 697-8-26.

Kool, W., McGuire, J.T., Rosen, Z.B., \& Botvinick, M.M. (2010) Decision making and the avoidance of cognitive demand. J. Exp. Psychol., 139, 665-682.

Krawczyk, D.C. (2002) Contributions of the prefrontal cortex to the neural basis of human decision making. Neurosci. Biobehav. Rev., 26, 631-664.

Kringelbach, M.L. (2005) The human orbitofrontal cortex: linking reward to hedonic experience. Nat. Neurosci., 6, 691-702.

Kurniawan, I.T., Guitart-Masip, M., Dayan, P., \& Dolan, R.J. (2013) Effort and valuation in the brain: the effects of anticipation and execution. J. Neurosci., 33, 6160-6169.

Kurniawan, I.T., Seymour, B., Talmi, D., Yoshida, W., Chater, N., \& Dolan, R.J. (2010) Choosing to make an effort: the role of striatum in signaling physical effort of a chosen action. J. Neurophysiol., 104, 313-321.

Labroo, A.A. \& Kim, S. (2009) The "instrumentality" heuristic: why metacognitive difficulty is desirable during goal pursuit. Psychol. Sci., 20, 127-134.

Leotti, L.A., Iyengar, S.S., \& Ochsner, K.N. (2010) Born to choose: the origins and value of the need for control. Trends Cogn. Sci., 14, 457-463.

Liu, J.Z., Dai, T.H., Elster, T.H., Sahgal, V., Brown, R.W., \& Yue, G.H. (2000) Simultaneous measurement of human joint force, surface electromyograms, and functional MRI-measured brain activation. J. Neurosci. Methods, 101, 49-57.

Luce, R.D. (1959) Individual Choice Behavior. John Wiley \& Sons, Inc, New York, NY.

Lutz, K., Pedroni, A., Nadig, K., Luechinger, R., \& Jäncke, L. (2012) The rewarding value of good motor performance in the context of monetary incentives. Neuropsychologia, 50, 1739-1747.

Ma, Q., Meng, L., Wang, L., \& Shen, Q. (2014) I endeavor to make it: effort increases valuation of subsequent monetary reward. Behav. Brain Res., 261, 1-7.

McClelland, D.C. (1985) How motives, skills, and values determine what people do. Am. Psychol., 41, 812-825.

McGuire, J.T. \& Botvinick, M.M. (2010) Prefrontal cortex, cognitive control, and the registration of decision costs. Proc. Natl. Acad. Sci. U. S. A., 107, 7922-7926.

Meyniel, F., Sergent, C., Rigoux, L., Daunizeau, J., \& Pessiglione, M. (2013)

Neurocomputational account of how the human brain decides when to have a break. Proc. Natl. Acad. Sci. U. S. A., 110, 2641-2646. 
Mitchell, D.G. V (2011) The nexus between decision making and emotion regulation: A review of convergent neurocognitive substrates. Behav. Brain Res., 217, 215-231.

Mochon, D., Norton, M.I., \& Ariely, D. (2012) Bolstering and restoring feelings of competence via the IKEA effect. Int. J. Res. Mark., 29, 363-369.

Nęcka, E., Lech, B., Sobczyk, N., \& Śmieja, M. (2012) How much do we know about our own cognitive control? Self-report and performance measures of executive functions. Eur. $J$. Psychol. Assessmen, 28, 240-247.

Nieuwenhuis, S., Heslenfeld, D.J., Alting von Geusau, N.J., Mars, R.B., Holroyd, C.B., \& Yeung, N. (2005) Activity in human reward-sensitive brain areas is strongly context dependent. Neuroimage, 25, 1302-1309.

Padoa-Schioppa, C. \& Cai, X. (2011) The orbitofrontal cortex and the computation of subjective value: consolidated concepts and new perspectives. Ann. N. Y. Acad. Sci., 1239, 130-137.

Prévost, C., Pessiglione, M., Météreau, E., Cléry-Melin, M.-L., \& Dreher, J.-C. (2010) Separate valuation subsystems for delay and effort decision costs. J. Neurosci., 30, 14080-14090.

Ryan, R. \& Deci, E. (2000a) Intrinsic and Extrinsic Motivations: Classic Definitions and New Directions. Contemp. Educ. Psychol., 25, 54-67.

Ryan, R.M. \& Deci, E.L. (2000b) Self-determination theory and the facilitation of intrinsic motivation, social development, and well-being. Am. Psychol., 55, 68-78.

Satterthwaite, T.D., Ruparel, K., Loughead, J., Elliott, M.A., Gerraty, R.T., Calkins, M.E., Hakonarson, H., Gur, R.C., Gur, R.E., \& Wolf, D.H. (2012) Being right is its own reward: Load and performance related ventral striatum activation to correct responses during a working memory task in youth. Neuroimage, 61, 723-729.

Schmidt, L., Braun, E.K., Wager, T.D., \& Shohamy, D. (2014) Mind matters: placebo enhances reward learning in Parkinson's disease. Nat. Neurosci., 17, 1793-1797.

Schmidt, L., Lebreton, M., Clery-Melin, M.L., Daunizeau, J., Pessiglione, M., \& Cléry-Melin, M.-L. (2012) Neural mechanisms underlying motivation of mental versus physical effort. PLoS Biol., 10, e1001266.

Schneider, W., Eschman, A., \& Zuccolotto, A. (2002) E-primeuser'sguide. Psychological Software ToolsInc., Pittsburgh.

Schouppe, N., Demanet, J., Boehler, C.N., Ridderinkhof, K.R., \& Notebaert, W. (2014) The role of the striatum in effort-based decision-making in the absence of reward. J. Neurosci., 34, $2148-2154$.

Schwarz, G. (1978) Estimating the Dimension of a Model. Ann. Stat., 6, 461-464.

Sescousse, G., Caldú, X., Segura, B., \& Dreher, J.-C. (2013) Processing of primary and secondary rewards: a quantitative meta-analysis and review of human functional neuroimaging studies. Neurosci. Biobehav. Rev., 37, 681-696.

Singer, R.A., Berry, L.M., \& Zentall, T.R. (2007) Preference for a stimulus that follows a relatively aversive event: Contrast or delay reduction? J. Exp. Anal. Behav., 87, 275-285.

Skvortsova, V., Palminteri, S., \& Pessiglione, M. (2014) Learning to minimize efforts versus maximizing rewards: computational principles and neural correlates. J. Neurosci., 34, 15621-15630. 
Smith, D. V, Rigney, A.E., \& Delgado, M.R. (2016) Distinct Reward Properties are Encoded via Corticostriatal Interactions. Sci. Rep., 6, 20093.

Stoppel, C.M., Boehler, C.N., Strumpf, H., Heinze, H.-J.J., Hopf, J.-M.M., \& Schoenfeld, M.A. (2011) Neural processing of reward magnitude under varying attentional demands. Brain Res., 1383, 218-229.

Talairach, J. \& Tournoux, P. (1998) Co-Planar Stereotaxic Atlas O Fthe Human Brain: An Approach to Medical Cerebral Imaging. Thieme Medical Publishers., Stuttgart, New York.

Tricomi, E., Delgado, M.R., \& Fiez, J.A. (2004) Modulation of caudate activity by action contingency. Neuron, 41, 281-292.

Tricomi, E., Delgado, M.R., McCandliss, B.D., McClelland, J.L., \& Fiez, J.A. (2006) Performance feedback drives caudate activation in a phonological learning task. J. Cogn. Neurosci., 18, 1029-1043.

Tricomi, E. \& Fiez, J.A. (2012) Information content and reward processing in the human striatum during performance of a declarative memory task. Cogn. Affect. Behav. Neurosci., 12, 361-372.

Tricomi, E. \& Fiez, J.A. (2008) Feedback signals in the caudate reflect goal achievement on a declarative memory task. Neuroimage, 41, 1154-1167.

Tricomi, E. \& Lempert, K.M. (2015) Value and probability coding in a feedback-based learning task utilizing food rewards. J. Neurophysiol., 113, 4-13.

Ullsperger, M. \& von Cramon, D.Y. (2003) Error monitoring using external feedback: specific roles of the habenular complex, the reward system, and the cingulate motor area revealed by functional magnetic resonance imaging. J. Neurosci., 23, 4308-4314.

Walton, M.E., Bannerman, D.M., Alterescu, K., \& Rushworth, M.F.S. (2003) Functional specialization within medial frontal cortex of the anterior cingulate for evaluating effortrelated decisions. J. Neurosci., 23, 6475-6479.

Westbrook, A. \& Braver, T.S. (2015) Cognitive effort: A neuroeconomic approach. Cogn. Affect. Behav. Neurosci., 15, 395-415.

Westbrook, A., Kester, D., \& Braver, T.S. (2013) What is the subjective cost of cognitive effort? Load, trait, and aging effects revealed by economic preference. PLoS One, 8, e68210.

Young, J.J. \& Shapiro, M.L. (2011) The orbitofrontal cortex and response selection. Ann. N. Y. Acad. Sci., 1239, 25-32.

Zentall, T.R. \& Singer, R.A. (2007) Within-trial contrast: Pigeons prefer conditioned reinforcers that follow a relatively more rather than a less aversive event. J. Exp. Anal. Behav., 88, 131-149. 


\section{Figure captions}

Figure 1. Depiction of trials for 1-step (low effort) and 2-step (high effort) conditions. 1-step random and 2-step random conditions resembled the above set-up; however, random feedback did not reflect performance accuracy.

Figure 2. A. Accuracy for the two learning conditions. There is a significant difference in performance between the 1-step (low effort) and 2-step (high effort) conditions. B. Learning accuracy by block for the two learning conditions. Chance performance is at $25 \%$.

Figure 3. A. Brain activity showing sensitivity to positive vs. negative feedback presentation (difficulty and contingency collapsed) ( $\mathrm{p}<0.05$, corrected for multiple comparisons). B. For illustrative purposes, beta weights from the voxels of the left VS showing sensitivity to positive vs. negative feedback

Figure 4. Beta weights from the voxels of the left VS showing an effect of high > low effort. Random conditions are included in the contrast as a control.

Supplementary Figure 1. Reaction time for the two learning and two random conditions. A significant interaction of difficulty and contingency was observed, as well as a main effect of difficulty and contingency. 
Table 1

\begin{tabular}{lccccc} 
& $\begin{array}{c}\text { 1-step } \\
\text { learning }\end{array}$ & $\begin{array}{c}\text { 2-step } \\
\text { learning }\end{array}$ & $\begin{array}{c}\text { 1-step } \\
\text { random }\end{array}$ & $\begin{array}{c}\text { 2-step } \\
\text { random }\end{array}$ & $\begin{array}{c}\text { baseline } \\
\text { model }\end{array}$ \\
\hline$\lambda$ & 0.97 & 0.71 & 0.02 & 0.0 & NA \\
$1 / \theta$ & 0.97 & 2.1 & 0.18 & 10 & NA \\
BIC & 2494.3 & 2667.0 & 2693.8 & 2803.8 & 2683.9 \\
\hline
\end{tabular}


Table 2. Regions showing the valence sensitivity (positive vs. negative feedback presentation) ( $p$ $<0.05$, corrected).

\begin{tabular}{lcccccc} 
& $\begin{array}{c}\text { Cluster size } \\
\left(\mathrm{mm}^{3}\right)\end{array}$ & Hemisphere & X & Y & Z & F \\
Region & & & & & & \\
\hline Bilateral Striatum/Ventromedial & 20999 & $\mathrm{~L}$ & -13 & 10 & -6 & 10 \\
Prefrontal Cortex & 5465 & $\mathrm{~L}$ & -43 & -56 & -6 & 5.6 \\
Cerebellum, Declive & 1308 & $\mathrm{R}$ & 11 & -98 & 6 & 4.5 \\
Cuneus (BA 16) & 1272 & $\mathrm{R}$ & 20 & -32 & -21 & 5.3 \\
Cerebellum, Culmen & & & & & & \\
Dorsolateral Prefrontal Cortex & 1167 & $\mathrm{R}$ & 50 & 34 & 12 & 5 \\
(BA 46) & 796 & $\mathrm{R}$ & 32 & -8 & -24 & 4.9 \\
Hippocampus & 432 & $\mathrm{~L}$ & -22 & -83 & -30 & 4.2 \\
Cerebellum, Posterior Lobe & 376 & $\mathrm{R}$ & 44 & -2 & 33 & 4.9 \\
Precentral Gyrus (BA 6) & 323 & $\mathrm{R}$ & 14 & -86 & 39 & 4.6 \\
Cuneus (BA 19) & & $\mathrm{R}$ & 56 & -62 & 3 & 4.7 \\
Middle Temporal Gyrus (BA & 311 & $\mathrm{R}$ & 32 & -74 & -24 & 4.5 \\
37) & 288 & $\mathrm{~L}$ & -16 & -98 & 6 & 4.2 \\
Cerebellum, Uvula & 246 & $\mathrm{R}$ & 8 & -86 & -27 & 4.1 \\
Cuneus (BA 16) & 145 & $\mathrm{~L}$ & -31 & -35 & -21 & 4.1 \\
Cerebellum, Pyramis & 137 & $\mathrm{R}$ & 8 & 43 & 30 & 4.1 \\
Cerebellum, Anterior Lobe & 114 & & & & & \\
Dorsomedial Prefrontal Cortex & & & & & \\
(BA 9) & & & & & & \\
\hline
\end{tabular}


Table 3a

Regions activated for the 1-step learning condition with PE as a regressor ( $p<0.05$, corrected).

\begin{tabular}{|c|c|c|c|c|c|c|}
\hline Region & Cluster size $\left(\mathrm{mm}^{3}\right)$ & Hemisphere & Peak x & Peak y & Peak z & Peak t \\
\hline Cerebellar Tonsil & 3695 & $\mathrm{~L}$ & -46 & -53 & -33 & 6.2 \\
\hline Cerebellum, Pyramis & 3108 & $\mathrm{~L}$ & -16 & -80 & -30 & 4.7 \\
\hline $\begin{array}{l}\text { Caudate Body } \\
\text { Posterior Cingulate }\end{array}$ & 1301 & $\mathrm{R}$ & 14 & 7 & 9 & 4.0 \\
\hline Cortex & 1018 & $\mathrm{~L}$ & -10 & -32 & 12 & 4.6 \\
\hline Occipital Lobe (BA 19) & 821 & $\mathrm{~L}$ & -4 & -89 & 39 & 5.0 \\
\hline $\begin{array}{l}\text { Cuneus (BA 7) } \\
\text { Dorsal Anterior }\end{array}$ & 481 & $\mathrm{R}$ & 5 & -71 & 30 & 3.9 \\
\hline $\begin{array}{l}\text { Cingulate } \\
\text { Ventrolateral Prefrontal }\end{array}$ & 409 & $\mathrm{~L}$ & -22 & 34 & 12 & 3.9 \\
\hline $\begin{array}{l}\text { Cortex (BA 10) } \\
\text { Inferior Parietal Lobule }\end{array}$ & 249 & $\mathrm{R}$ & 26 & 52 & -9 & 4.0 \\
\hline (BA 7) & 240 & $\mathrm{R}$ & 8 & -47 & 45 & 4.3 \\
\hline $\begin{array}{l}\text { Cerebellum, Culmen } \\
\text { Cerebellum, Lateral }\end{array}$ & 233 & $\mathrm{~L}$ & -13 & -38 & -9 & 3.7 \\
\hline $\begin{array}{l}\text { Declive } \\
\text { Cerebellum, Lateral }\end{array}$ & 221 & $\mathrm{R}$ & 32 & -83 & -18 & 3.4 \\
\hline $\begin{array}{l}\text { Declive } \\
\text { Cerebellum, Middle }\end{array}$ & 219 & $\mathrm{~L}$ & -37 & -89 & -18 & 3.8 \\
\hline $\begin{array}{l}\text { Declive } \\
\text { Inferior Temporal }\end{array}$ & 172 & $\mathrm{R}$ & 14 & -83 & -21 & 3.6 \\
\hline $\begin{array}{l}\text { Gyrus (BA 20) } \\
\text { Posterior Cingulate }\end{array}$ & 134 & $\mathrm{~L}$ & -67 & -26 & -18 & 4.3 \\
\hline Cortex & 114 & $\mathrm{R}$ & 5 & -32 & 15 & 3.9 \\
\hline
\end{tabular}


Table $3 b$

Regions activated for the 2-step learning condition with PE as a regressor ( $p<0.05$, corrected).

\begin{tabular}{|c|c|c|c|c|c|c|}
\hline Region & Cluster Size $\left(\mathrm{mm}^{3}\right)$ & Hemisphere & Peak X & Peak Y & Peak Z & Peak $\mathrm{t}$ \\
\hline \multicolumn{7}{|l|}{ Medial } \\
\hline \multicolumn{7}{|l|}{ Prefrontal } \\
\hline Cortex (BA 9) & 3492 & $\mathrm{~L}$ & -13 & 46 & 18 & 5.2 \\
\hline \multicolumn{7}{|l|}{ Inferior Frontal } \\
\hline Gyrus (BA 47) & 2375 & $\mathrm{R}$ & 38 & 22 & -6 & 4.8 \\
\hline Cuneus (BA 18) & 1586 & $\mathrm{R}$ & 5 & -89 & 18 & 3.8 \\
\hline \multicolumn{7}{|l|}{ Dorsolateral } \\
\hline \multicolumn{7}{|l|}{ Prefrontal } \\
\hline Cortex (BA 9) & 1384 & $\mathrm{R}$ & 56 & 16 & 21 & 4.9 \\
\hline \multicolumn{7}{|l|}{ Anterior } \\
\hline \multicolumn{7}{|l|}{ Cingulate } \\
\hline Cortex (BA 24) & 1358 & $\mathrm{R}$ & 11 & 19 & 21 & 4.2 \\
\hline \multicolumn{7}{|l|}{ Middle } \\
\hline $\begin{array}{l}\text { Occipital Gyrus } \\
\text { (BA 19) }\end{array}$ & 897 & $\mathrm{R}$ & 23 & -65 & -6 & 5.2 \\
\hline \multicolumn{7}{|l|}{ Superior } \\
\hline \multicolumn{7}{|l|}{ Temporal Gyrus } \\
\hline \multicolumn{7}{|l|}{ Supplementary } \\
\hline \multicolumn{7}{|l|}{ Motor Area (BA } \\
\hline 6) & 321 & $\mathrm{~L}$ & -7 & 28 & 51 & 3.8 \\
\hline \multicolumn{7}{|l|}{ Superior } \\
\hline $\begin{array}{l}\text { Temporal Gyrus } \\
\text { (BA 41) }\end{array}$ & 267 & $\mathrm{~L}$ & -46 & 28 & 3 & 3.4 \\
\hline Insula (BA 13) & 235 & $\mathrm{~L}$ & -37 & 22 & -9 & 4.0 \\
\hline \multicolumn{7}{|l|}{ Superior } \\
\hline \multicolumn{7}{|l|}{ Temporal Gyrus } \\
\hline \multicolumn{7}{|l|}{ Middle } \\
\hline \multicolumn{7}{|l|}{ Occipital Gyrus } \\
\hline \multicolumn{7}{|l|}{ Superior Frontal } \\
\hline Gyrus (BA 8) & 179 & $\mathrm{R}$ & 5 & 40 & 42 & 3.5 \\
\hline \multicolumn{7}{|l|}{ White } \\
\hline Matter/Insula & 173 & $\mathrm{R}$ & 29 & 16 & 21 & 3.8 \\
\hline \multicolumn{7}{|l|}{ Primary Motor } \\
\hline Cortex (BA 4) & 172 & $\mathrm{~L}$ & -7 & -8 & 69 & 4.0 \\
\hline \multicolumn{7}{|l|}{ Cerebellar } \\
\hline \multicolumn{7}{|l|}{ Tonsil, } \\
\hline Cerebellum & 172 & $\mathrm{R}$ & 23 & -53 & -42 & 4.5 \\
\hline \multicolumn{7}{|l|}{ Supplementary } \\
\hline \multicolumn{7}{|l|}{ Motor Area (BA } \\
\hline 6) & 142 & $\mathrm{R}$ & 8 & 19 & 48 & 4.1 \\
\hline White & & & & & & \\
\hline Matter/Rostral & 113 & $\mathrm{~L}$ & -7 & 25 & 3 & 3.9 \\
\hline
\end{tabular}


Anterior

Cingulate

Inferior Frontal

Gyrus (BA 45)

Ventrolateral

106

L

$-43$

22

15

3.5

Prefrontal

Cortex (BA 10)

103

$\mathrm{R}$

44

46

0 
Table 3c

Regions identified by the contrast of PE of the 2-step learning positive versus 1-step learning positive feedback presentation $(\mathrm{p}<0.05$, corrected).

\begin{tabular}{lcccrrr} 
Region & Cluster size $\left(\mathrm{mm}^{3}\right)$ & Hemisphere & Peak X & Peak Y & Peak X & Peak t \\
\hline Inferior Frontal & & & & & & \\
Gyrus (BA 44) & 853 & $\mathrm{R}$ & 56 & 16 & 18 & 4.1 \\
$\begin{array}{l}\text { Insula } \\
\text { Medial Frontal }\end{array}$ & 853 & $\mathrm{R}$ & 38 & 19 & -6 & 4.2 \\
$\begin{array}{l}\text { Gyrus (BA 9) } \\
\text { Inferior Frontal }\end{array}$ & 686 & $\mathrm{~L}$ & -13 & 46 & 18 & 4.6 \\
$\begin{array}{l}\text { Gyrus (BA 47) } \\
\text { Inferior Frontal }\end{array}$ & 500 & $\mathrm{R}$ & 26 & 34 & 3 & 4.4 \\
$\begin{array}{l}\text { Gyrus (BA 45) } \\
\text { Precentral Gyrus }\end{array}$ & 301 & $\mathrm{~L}$ & -46 & 28 & 6 & 3.7 \\
$\begin{array}{l}\text { Fusiform Gyrus } \\
\text { (BA 19) }\end{array}$ & 200 & $\mathrm{~L}$ & -52 & -5 & 12 & 3.8 \\
$\begin{array}{l}\text { White } \\
\text { Matter/Cerebellum }\end{array}$ & 187 & $\mathrm{R}$ & 23 & -65 & -6 & 4.1 \\
\hline
\end{tabular}


Table 3d

Regions identified by the contrast of 2-step learning positive versus 1-step learning positive feedback presentation, with PE included in the model ( $\mathrm{p}<0.05$, corrected).

\begin{tabular}{|c|c|c|c|c|c|c|}
\hline Region & $\begin{array}{l}\text { Cluster size } \\
\left(\mathrm{mm}^{3}\right)\end{array}$ & Hemisphere & Peak X & Peak Y & Peak Z & Peak t \\
\hline \multicolumn{7}{|l|}{ Ventromedial Prefrontal } \\
\hline \multicolumn{7}{|l|}{ Cortex/rostral Anterior } \\
\hline Cingulate Cortex & 13234 & $\mathrm{R}$ & 8 & 22 & 45 & 5.6 \\
\hline Superior Temporal Gyrus & & & & & & \\
\hline $\begin{array}{l}\text { (BA 42) } \\
\text { Ventrolateral Prefrontal }\end{array}$ & 3230 & $\mathrm{~L}$ & -58 & -32 & 18 & 4.8 \\
\hline Cortex (BA 10) & 1135 & $\mathrm{R}$ & 41 & 40 & -3 & 4.9 \\
\hline Inferior Frontal Gyrus & & & & & & \\
\hline $\begin{array}{l}\text { (BA 47) } \\
\text { Dorsal Posterior }\end{array}$ & 1049 & $\mathrm{R}$ & 38 & 19 & -9 & 4.9 \\
\hline Cingulate Cortex & 797 & $\mathrm{~L}$ & -7 & -50 & 33 & 4.1 \\
\hline $\begin{array}{l}\text { Inferior Temporal Gyrus } \\
\text { (BA 20) }\end{array}$ & 706 & $\mathrm{R}$ & 56 & 22 & 9 & 4.3 \\
\hline Dorsolateral Prefrontal & & & & & & \\
\hline Cortex (BA 46) & 659 & $\mathrm{~L}$ & -43 & 37 & 6 & 3.8 \\
\hline Dorsal Middle Temporal & & & & & & \\
\hline Gyrus (BA 21) & 498 & $\mathrm{R}$ & 59 & -35 & -12 & 4 \\
\hline Dorsolateral Prefrontal & & & & & & \\
\hline Cortex (BA 9) & 370 & $\mathrm{R}$ & 20 & 49 & 30 & 4 \\
\hline Supplementary Motor & & & & & & \\
\hline Area (BA 6) & 172 & $\mathrm{~L}$ & -43 & 4 & 42 & 3.6 \\
\hline Middle Temporal Gyrus & & & & & & \\
\hline (BA 21) & 165 & $\mathrm{R}$ & 62 & -17 & -12 & 4.2 \\
\hline Medial Prefrontal Cortex & & & & & & \\
\hline (BA 10) & 146 & $\mathrm{~L}$ & -28 & 37 & 21 & 3.6 \\
\hline Inferior Frontal Gyrus & & & & & & \\
\hline (BA 47) & 134 & $\mathrm{~L}$ & -37 & 25 & -9 & 3.4 \\
\hline $\begin{array}{l}\text { Inferior Frontal Gyrus } \\
\text { (BA 45) }\end{array}$ & 132 & $\mathrm{~L}$ & -43 & 19 & 15 & 3.6 \\
\hline Middle Temporal Gyrus & & & & & 0 & 34 \\
\hline $\begin{array}{l}\text { (BA 21) } \\
\text { Cerebellar Tonsil }\end{array}$ & $\begin{array}{c}117 \\
80\end{array}$ & $\begin{array}{l}\mathrm{L} \\
\mathrm{D}\end{array}$ & $\begin{array}{r}-58 \\
26\end{array}$ & $\begin{array}{r}-44 \\
52\end{array}$ & $\begin{aligned} 0 \\
-12\end{aligned}$ & $\begin{array}{l}3.4 \\
3.0\end{array}$ \\
\hline Cerebellar Tonsil & 80 & $\mathrm{R}$ & 26 & -53 & -42 & 3.9 \\
\hline
\end{tabular}


Figure 1

Trial Examples from Learning Conditions

1-step Learning
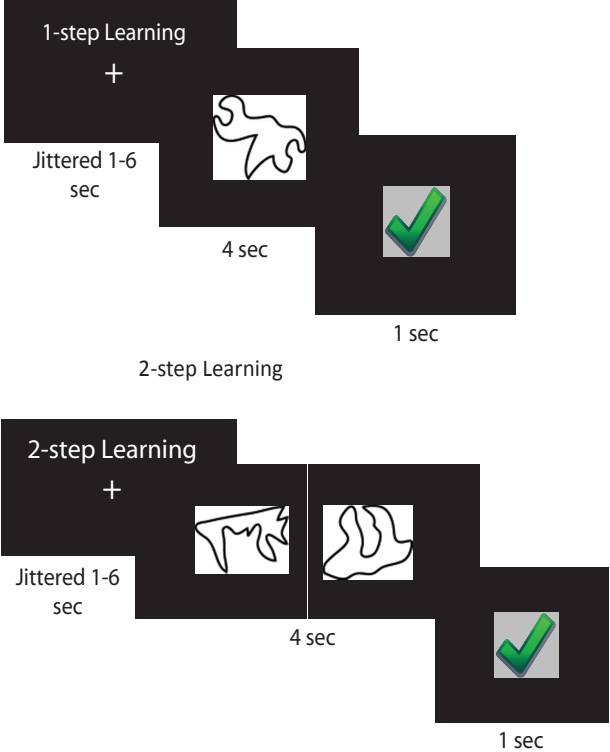
Figure 2

A

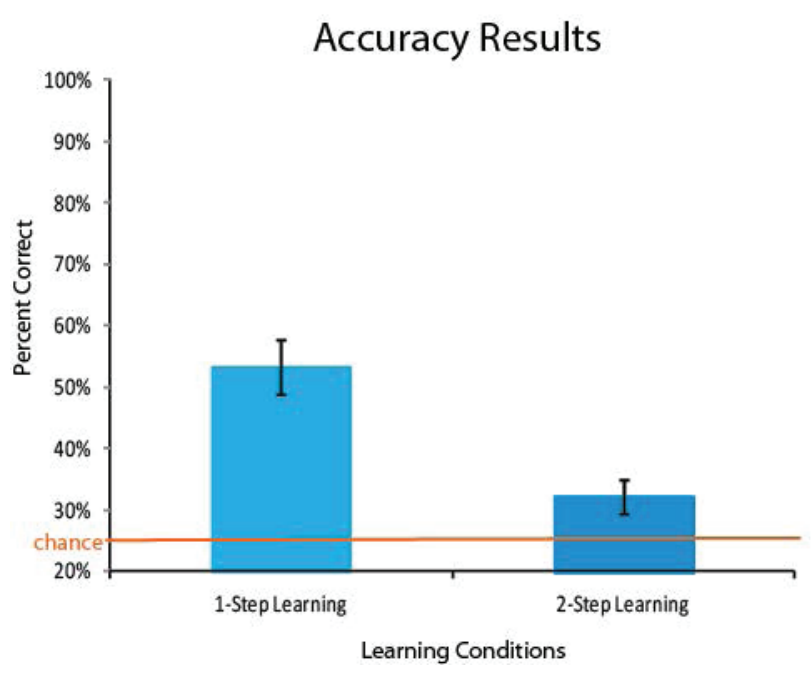

B

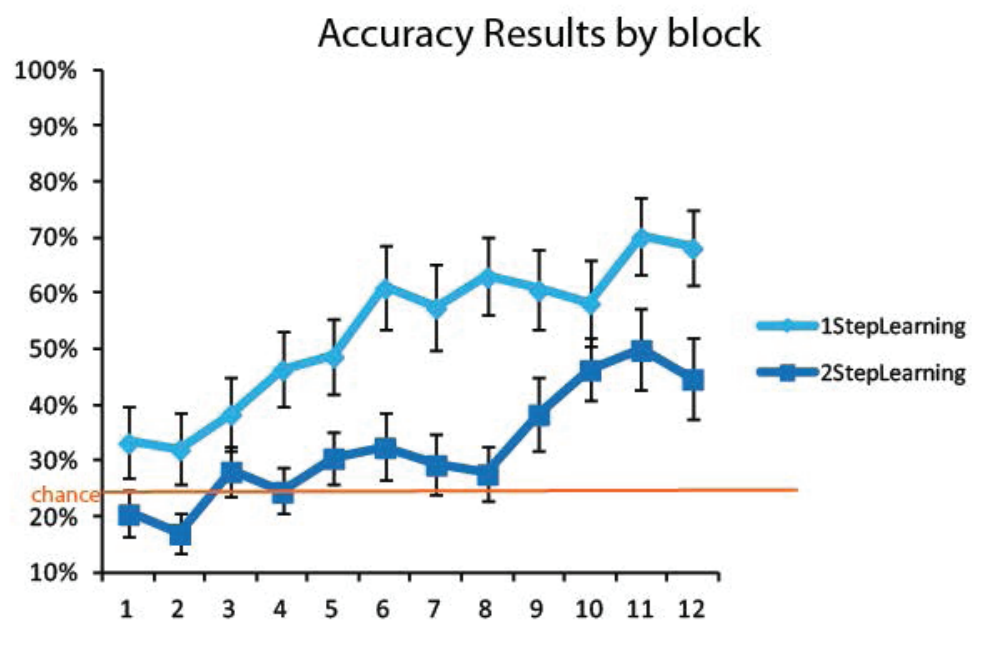


Figure 3

A

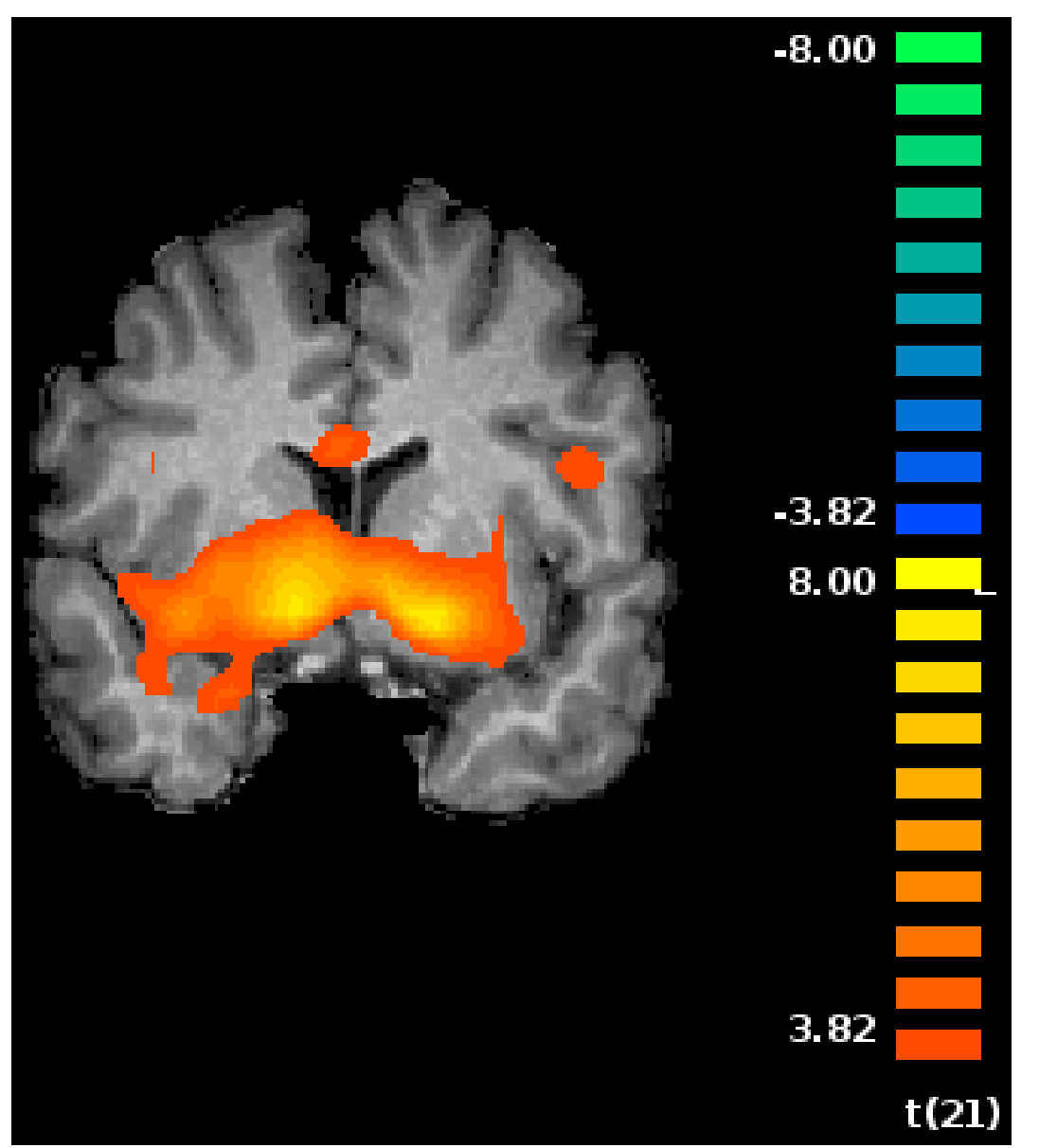

B

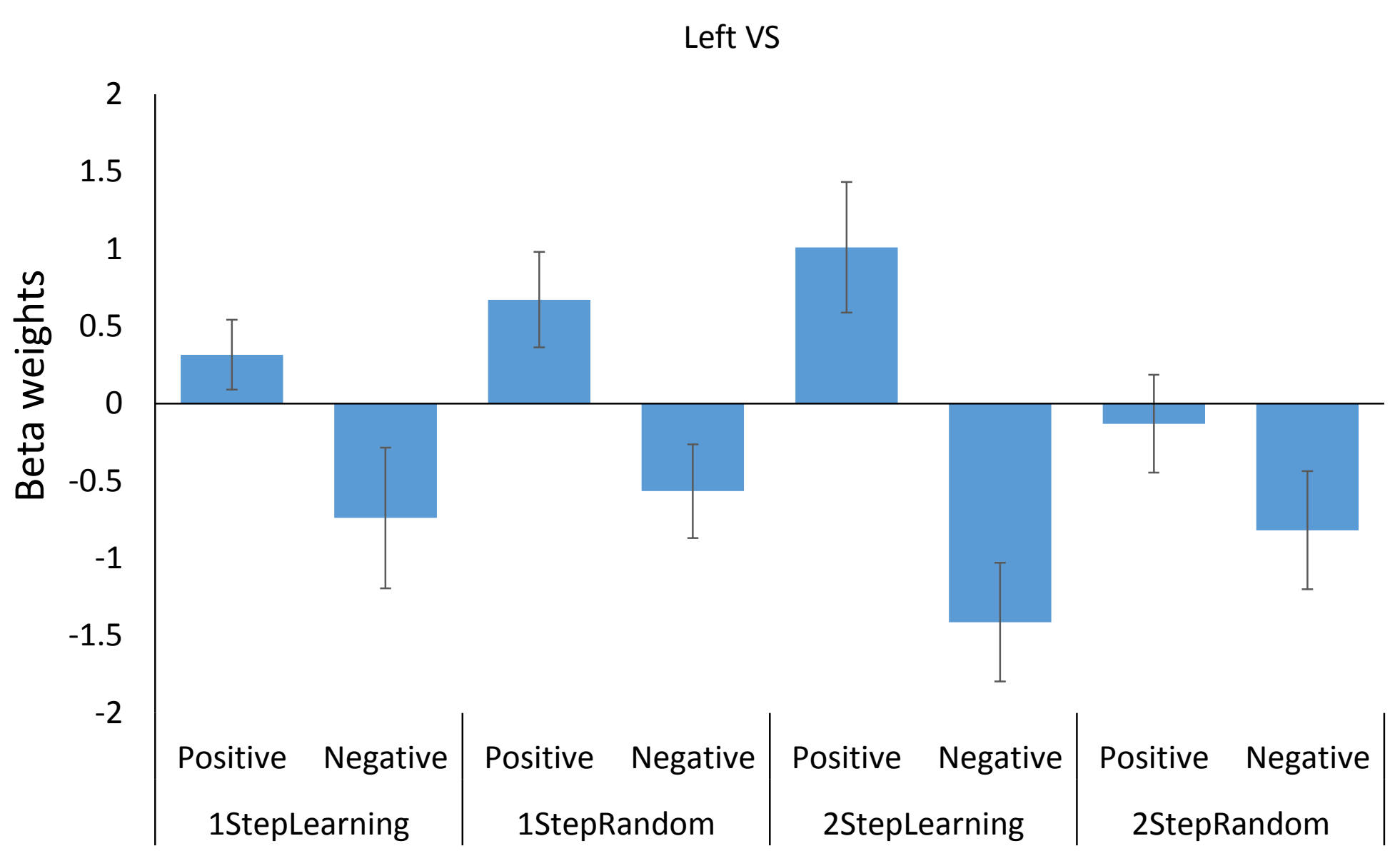




\section{Figure 4}

Left VS

2

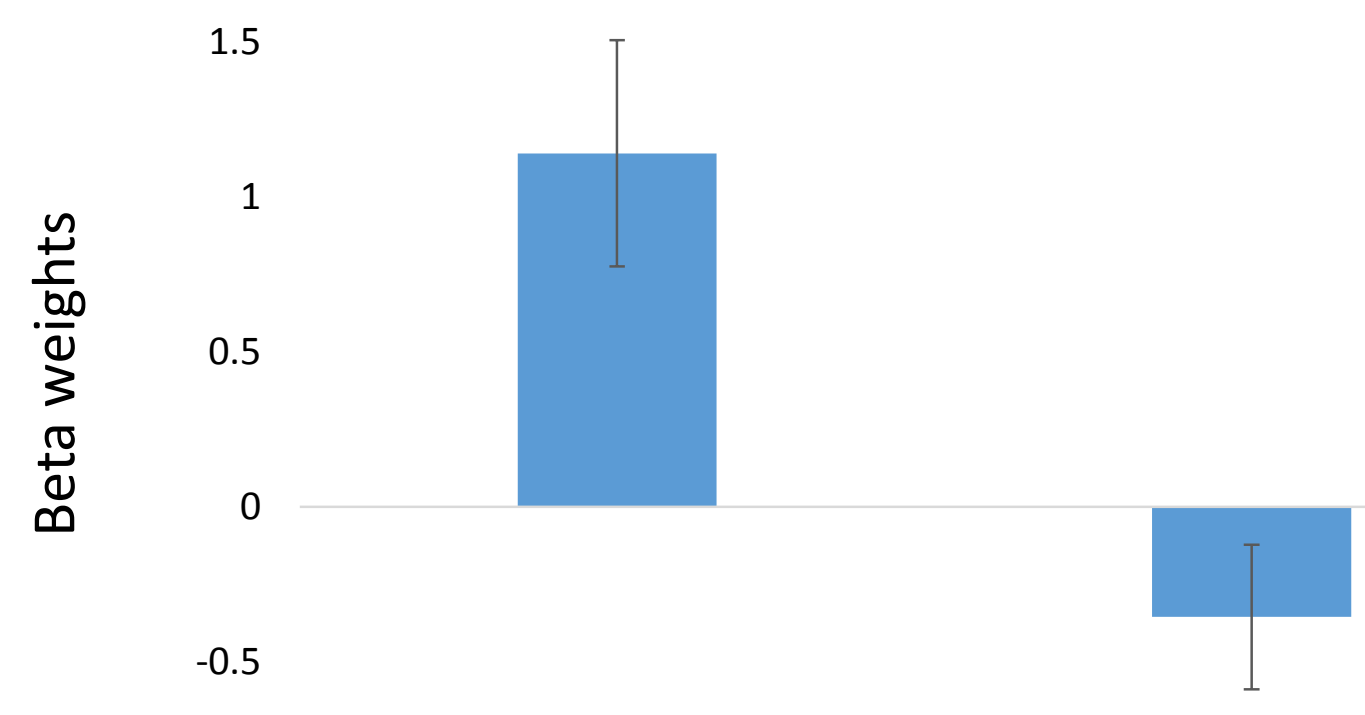

$-1$

High Effort

Low Effort 